\title{
RELEVANSI WAYANG KULIT SEBAGAI MEDIA DAKWAH DI ERA MODERN: Studi Tentang Media Dakwah
}

\author{
Agus Fatuh Widoyo \\ Fakultas Dakwah, Institut Islam Mamba’ul ‘Ulum Surakarta \\ e-mail: agusfatuh04@gmail.com
}

\begin{abstract}
In modern life, wayang can have a dual function, namely as a medium to fulfill spiritual needs and at the same time as entertainment. This is because modern humans experience alienation, which is a feeling of loneliness in the crowd around them. This is what makes wayang kulit remain relevant in the modern world to become a medium of da'wah. The art of wayang culture is the original work of the Indonesian people, especially Java. The art of wayang kulit is currently the identity of the Indonesian nation. Wayang in its current form is a precious heritage for Muslims.
\end{abstract}

Keywords: wayang, da'wah, modern

\section{PENDAHULUAN}

Wayang sebagai bagian dari media dakwah kulutral, pemanfaatannya dalam proses Islamisasi masyarakat Indonesia, khususnya dalam proses Islamisasi masyarakat Indonesia, khususnya di Jawa sudah berlangsung sejak awal masuknya Islam ditanah air. Arifin, menjelaskan, dakwah kultural adalah dakwah yang dilakukan dengan cara mengikuti budayabudaya kultural masyarakat setempat dengan tujuan agar dakwah nya dapat diterima di lingkungan masyarakat setempat, dalam rangka menghasilkan kultur baru yang bernuansa Islami dengan memanfaatkan adat, tradisi, seni dan budaya lokal dalam proses menuju kehidupan yang Islami. ${ }^{1}$ Di masa Rasulullah, dalam dakwahnya beliau juga terkadang menggunakan pendekatan kultural, yakni dakwah yang menghargai keragaman suku kebudayaan serta juga pengalaman terhadap berbagai model keberamagaman seseorang untuk mewujudkan Islam rahmatan lil'alamin. ${ }^{2}$

Pendekatan dakwah berbasis kultural yang dianut Walisongo termasuk sunan Kalijaga adalah dakwah yang terlebih dakwah mengutamakan aspek amar ma'ruf, baru kemudian nahi mungkar, sehingga akomdatif terhadap segala aspirasi yang berkembang, diantaranya yaitu mengakomodasi wayang sebagai media dakwah, karena saat itu masyarakat sangat menyukai wayang. ${ }^{3}$ Di tangan Walisongo, wayang model Hindu-Budha dimodifikasi sedemikian rupa agar tidak bertentangan dengan syari'at Islam. Tujuan diadakannya modifikasi bentuk wayang dari yang semula berciri khas Hindu-Budha menjadi bernuansa Islam adalah untuk memberantas kemusyrikan dari ajaran lama. Ini terjadi di masa Kerajaan Islam Demak. Selanjutnya Walisongo menerapkan ajaran Islam kepada masyarakat secara murni namun dilakukan secara bertahap. ${ }^{4}$ Hal ini dilakukan, untuk disesuaikan dengan tingkat pemahaman mereka terhadap ajaran Islam.

\footnotetext{
${ }^{1}$ Muhammad Arifin, Dakwah Kontemporer, (Surabaya: Pustaka Agung Harapan, 2004). hal. 3

${ }^{2}$ Muslim Abdurrahman. Muhammadiyah Tenda Kultural, (Idio Press dan maarif Institut for Culture and humanity: 2003). Cet, 1, hal. 26

${ }^{3}$ Purwadi, Dakwah Sunan Kalijaga, (Yogya: Pustaka Pelajar, 2007). hal. 72-73

${ }^{4}$ Ibid., hal. 177
} 
Walisongo dalam pendekatan dakwahnya yang berbasis kultural, menerapkan prinsipprinsip sebagai berikut: Agar masyarakat Hindu-Budha menerima Islam, dakwah harus dilakukan dengan bijaksana, secara pelan-pelan bertahap sehingga hatinya tetap tenang terbuka; Ajaran Islam yang disampaikan harus sedikit demi sedikit; Diusahakan agar masyarakat cinta Islam lebih dahulu, baru kemudian diarahkan ke syari'at, thariqat, hakekat sampai makrifat. ${ }^{5}$ Dalam penyampaian ajaran Islam kepada masyarakat (mad'u), dapat dilakukan melalui berbagai media (wasilah). Hamzah Ya'kub ${ }^{6}$ membagi media dakwah menjadi lima, yaitu: Melalui lisan, seperti cermaha, kuliah dan pidato; Melalui tulisan, seperti buku, majalah, surat kabar, korespondensi dan spanduk; Melalui lukisan, misalnya gambar, dan karikatur; Melalui audio visual seperti TV, film, internet, sllide dan OHP; Akhlaq, misalnya kunjungan silaturahmi.

Berdasarkan pembagian ini, maka kesenian wayang kulit termasuk dalam kelompok media dakwah audio visual. Ini terlihat dalam pementasan wayang di dalanya ada unsur suara dalang siraman gamelan (audio) dan permainan wayang (visual) yang berpadua secara serempak. Media dakwah dari segi sifatnya, menurut Ali Aziz ${ }^{7}$ ada dua yaitu media dakwah tradisional dan media dakwah modern. Berdasarkan pembagian Aziz ini, maka kesenian wayang termasuk dalam golongna media dakwah tradisional. Di era global, media dakwah tersedia bermacam-macam ragamnya, sebagian masyarakat masih menyukai dengan menerima media kultural yang bersifat tradisional, seperti kesenian wayang, ketoprak, ludruk, hadrah/rebana dan sebagainya. Sedangkan sebagian masyarakat yang lain lebih menyukai media dakwah kontemporer yang bersifat modern seperti film, drama, opera, telenovela dan sebagainya. Dengan demikian secara faktual dan realitas, baik media yang bersifat tradisional maupun yang modern, kberadaanya tetap dibutuhkan untuk memfasilitasi pelaksanaan aktifitas dakwah, karena masing-masing jenis media tersebut memiliki segmen sendiri dalam masyarakat. ${ }^{8}$

\section{PEMBAHASAN}

\section{Media Dakwah}

1. Arti Media Dakwah

Kata media berasal dari bahasa latin median, yang merupakan bentuk jamak dari media yang berarti alat atau perantara. Secara lebih sepesifik, menurut Munir ${ }^{9}$, media adalah alat-alat fisik yang menjelaskan isi pesan atau pengajaran seperti buku, film, video, kaset, slide dan sebagainya. Adapun yang dimaksud media dakwah (wasilah al-dakwah) menurut Wardi Bachtiar adalah praktek yang di pergunakan untuk menyampaikan materi dakwah kepada pemerima dakwah. ${ }^{10}$ Dalam hal ini media yang dimaksudkan dalam makalah ini adalah kesenian wayang.

\footnotetext{
${ }^{5}$ Zarkasi, Efendi, Unsur-unsur Islam dalam Pewayangan, (Solo: Yayasan Mardi Kintoho,1996), hal. 141142

${ }^{6}$ Ya'qub Hamzah, Publisistik Islam, (Bandung: CV. Diponegoro, 1981), hal. 98

${ }^{7}$ Ali Aziz, Ilmu Dakwah, (Jakarta, Prenada Media, 2004), hal. 199

${ }^{8}$ Muhammad Arifin, Dakwah Kontemporer, (Surabaya: Pustaka Agung Harapan,2004), hal. 4-6

${ }^{9}$ Munir, Muhammad, Metode Dakwah, (Jakarta, Prenada Media,2009). hal. 113

${ }^{10}$ Wardi Bachtiar, Wardi, Metodologi Penelitian Dakwah, (Jakarta: Logos, 1997). hal. 35
} 


\section{Bentuk-bentuk Media Dakwah}

Dari segi luasnya jangkauan obyek, media dibagi dua, yaitu: (1) Non Media Massa misalnya manusia; utusan, kurir, benda, telepon, surat; (2) Media Massa misalnya, media massa manusia; pertemanan, rapat umum, seminar dan lain-lain; media massa benda ; buku, spanduk, folder dan lain sebagainya; media massa periodik; cetak dan elektornik, visual, audio, audio visual. Berdasarkan pembagian ini, maka kesenian wayang bisa dikategorikan sebagai media massa benda dan manusia. Hal ini dikarenakan dalam penggunaannya, wayang tidak bisa lepas dari faktor manusia, yaitu si dalang $\left(d^{\prime}{ }^{\prime} i\right)$ yang mementaskannya dalam suatu sajian pertujunjukan (pergelaran).

\section{Wayang Kulit}

\section{Sejarah dan Pengertiannya}

Mengutip Joyowidagdo, Zarkasi) menyatakan, secara etimologi wayang diartikan sebagai ayang-ayang (bayangan) yang ada pada kelir karena sinar blencong. ${ }^{11}$ Pendapat yang lebih filosofis disampaikan oleh Sudarto, dalam pandangannya wayang diartikan sebagai wewayange urip. $^{12}$ Para sejarawan dalam menetapkan asal-muasal wayang berbeda-beda. Menurut Krom wayang berasal dari India, sedang Gosling berpendapat dari Cina. ${ }^{13}$ Sedangkan Pischel, sebagaimana dikutip Hazim, mendukung Gosling yakni wayang berasal dari India. ${ }^{14}$ Namun menurut sejarawan Belanda Hazeu, wayang berasal dari masyarakat Jawa sendiri di masa animisme. ${ }^{15}$

\section{Bentuk Wayang di Masa Pra Islam dan di Masa Islam}

Menurut data sejarah, pada tahun 937 M Raja Kediri Jayabaya memulai membuat wayang dari rontal. Raja Jenggala Raden Panji tahun 1223 M juga membuat wayang dengan bahan yang sama. Mulai tahun 1244 M Raja Lembu Amiluhur dari Pajajaran membuat wayang dari kertas. Demikian juga Prabu Brawijaya dari Majapahit pada tahun $1283 \mathrm{M}$ membuat wayang dari kertas berbentuk wayang beber. ${ }^{16}$ Bentuk wayang pada masa ini menyerupai manusia. Posisi wajahnya methok, sedangkan sumber ceritanya berasal dari Kitab Mahabarata dan Ramayana. Bentuk wayang di masa Islam mengalami perubahan, yakni disusaikan dengan ajaran Islam. Pada masa pra Islam, wayang berwujud arca-arca kecil seperti manusia. Menurut paham agama saat itu, menyimpan atau memeliharanya untuk hiasan atau apapun dinilai haram di masa awal-awal Islam masuk Jawa.

Menurut Pujosubroto, dalam masyarakat antara sultan demak pertama dengan Walisongo, diputuskan untuk memodifikasi bentuk wayang ke dalam bentuk yang jauh dari bentuk manusia. Untuk tokoh alusan, hidung dibuat lancip, leher sebesar lengan di panjang, lengan tangan panjang hampir menyentuh telapak kaki. ${ }^{17}$ Mulut dibuat berliku-liku. ${ }^{18}$

Secara historis wayang tidak lepas dari sunan Kalijaga, beliaulah yang telah berjasa memodifikasi wayang dari bentuk lama (Hindu-Budha) menjadi bentuk seperti yang sekarang

\footnotetext{
${ }^{11}$ Efendi Zarkasi, Unsur-unsur Islam dalam Pewayangan, (Solo: Yayasan Mardi Kintoko, 1996). hal. 5

${ }^{12}$ Amin Darori, Islam \& Kebudayan Jawa, (Yogya: Gama Media, 2000). hal. 172

${ }^{13}$ Sutrisno, Dunia Wayang dan Sejarahnya, (Surakarta: ASKI, 1972). Hal. 2-3

${ }^{14}$ Amir Hazmin, Nilai-nilai Etis Wayang, (Jakarta: Pustaka Sinar Harapan,1979). hal. 29

${ }^{15}$ Soetarno, Wayang Kulit Jawa, (Sukoharjo: Cendrawasih,1995). Hal. 5

${ }^{16}$ Martosoedono, Sejarah Wayang, (Semarang: Dahara Prize,1995). hal. 18

${ }^{17}$ Poejosubroto, Wayang Lambang Ajaran Islam, (Jakarta: Paramita, 1978). hal. 22

${ }^{18}$ Sunarto, Wayang Kulit Purwo Gaya Yogyakarta, (Jakarta: Balai Pustakaa, 1989). hal. 31
} 
Sunan Kalijaga menggunakan wayang sebagai salah satu jalan untuk mendapatkan dan menarik simpati rakyat agar mau masuk Islam secara sukarela.

3. Relevansi Wayang Sebagai Media Dakwah di Era Modern

a. Urgensi Modern

Dalam pandangan bangsa-bangsa lain, kesenian wayang diakui sebagai identitas kebudayaan bangsa Indonesia. Khususnya suku Jawa. Mereka tahu bahwa di dalam diri setiap tokoh wayang, dan dalam alur ceritanya mengandung ajaran nilai-nilai filosofis yang adiluhung, sehingga tidak mengherankan jika wayang dipandang sebagai brand image bagi bangsa Indonesia yang penting untuk terus dilestarikan.

Simuh mengemukakan ${ }^{19}$, antara budaya Jawa dan Wayang seperti dua sisi dalam satu keping mata uang, yakni saling beriringan. Masyarakat jawa memandang wayang sebagai refleksi kehidupan yang lengkap, sehingga tidak aneh jika wayang dianggap sebagai wewayange urip. Wayang sebagai sebuah karya seni sastra dapat menjadi sarana (media) yang paling efektif untuk memasyarakatkan nilai-nilai luhur yang ada dalam khazanah kebudayaan Jawa. Dengan demikian wayang memiliki fungsi ganda, yaitu sebagai tontonan (entertainment) dan tuntunan (education) dalam kehidupan masyarakat. Pelestarian kesenian wayang sebagai warisan adiluhung bangsa, diharapkan bisa menjadi sarana (media) untuk mendekatkan umat Islam jawa khsusunya, kepada budayanya sendiri, yang luhur dan mengandung istibar serta nilai-nilai filosifis ajaran Islam.

b. Keunggulan komperatif wayang sebagai media dakwah dibanding media lain

Keunguglan wayang sebagai media dakwah terletak data beberapa aspek yaitu: Aspek psikologis: Seni pewayangan lebih banyak menembuh per aspek dari pada sihir. Dengan begitu pemahaman ajaran Islam mudah masuk ke dalam hati/perasaan media. Penjabaran berita dan karakteri setiap tokohnya dengan perspektif Islam lebih mengena, karena tidak terkesan menggurui. Aspek Hirstoris; Wayang merupakan kegemarn rakyat sejak dulu, bukan saja di Jawa, namun juga di Malaysia. Penggemar (pandemen) wayang bukan saja masyarakat yang belum melek huruf. Namun juga kalangan well educated. Daerah dengan media wayang akan dapat menimbulkan apresiatif saling halangan umat Islam terhadap seni budaya wayang sebagai history and cultural dari tiga pendahulunya yang layak dihargai. Aspek pedagogis; Isi cerita wayang penuh dengan ajaran hidup bernilai luhur, maka wayang menjadi media untuk usaha terealissi dan sosialisasi penanaman nilai-nilai luhur tersebut, wal hasil wayang bisa berpartisipasi dalam mewujudkan bangsa yang berkarakter (national caracter building) untuk menunjang program pemerintah dalam bidang pendidikan yang berkarakter. Aspek politik; dengan media pewayangan, daerah Islam relatif tidak menemui kesulitan, bisa diterima semua golongan baik yang demam wayang maupun yang belum, jika dibandingkan media lain. Dakwah dengan wayang lebih bersifat fleksibel, karena realtif tidak terkendala oleh disper, tes pendidikan, status sosial, aspirasi politik dasan sebagainya. Aspek Praktis; Untuk kepentingan dakwah, seni pewayangan merupakan media yang praktis, karena sifatnya yang aplicable dan sudah familier dalam kehidupan masyarakat sejak dulu.

Disamping itu, seni wayang kulit memiliki add value dalam aspek ceri tanya. Nilai lebih itu berupa ajaran-ajaran hidup yang mencakupi:

${ }^{19}$ Simuh, Sufisme Jawa, (Yogyakarta: Bintang Budaya, 1999). hal. 118-119 
a. Kita harus percaya pada kekuasaan-Nya.

b. Filsafat, mencari hakikat kebenaran sejati.

c. Akhlaq moral, bahwa tindakan terpuji akhirnya akan mendapatkan kebagiaan, bagi tempt sebaliknya.

d. Heroisme, bahwa keberanian untuk membela kebenarna pasti jaya. Lain segala dengan konsep jihad dengan Islam.

e. Kenegaraan, bagai mana suatu negara harus diatur sebagaimana pejabat negara harus bertindak.

f. Cita-cita hidup, untuk menjaga kebahagiaan demi demokrasi. Demikian penjelasan Zarkasi. $^{20}$

Cakupan cerita wayang ini, spritinya segala nilai-nilai Islam. Hal ini bukan merupakan sesuatu yang kebetulan, namun sudah bersifat design sesuai tujuan arsiteknya yaitu wali songo. Ini terlihat dalam cerita-cerita karangan seperti lakon jimat kalimassada, mustahaweni, petruk dadi ratu, partodewa, dewa suci dan sebagainya.

4. Relevansi Wayang dengan Kehidupan Modern

Masalah satu gejala mengkhawatirkan yang menghinggapi kehidupan orang modern adalah alienasi, yaitu perasaan terasing meski berada di tengah kehidupan ramai, demikian menurut Muhammad Shulton. ${ }^{21}$ Di sisi lain, masyarakat modern juga membutuhkan hiburan. Agar kebutuhan rohani yang bersifat spiritual terpenuhi, dan kebutuhan akan hiburan juga terpenuhi, maka masyrakat modern membutuhkan suatu sarana (hiburan) yang berfungsi ganda, yakni yang bisa mengisi kegersangan rohani akan nilai-nilai spiritualitas keagamaan sekalipun juga hiburan. Untuk mengisi kebosanannya ini, snei budaya wayang kulit bias menjadi salah satu media alternatif di samping media yang lainnya. Dengan memperhatikan paparan dari dari uraian-uraian di atas, maka wayang kulit masih merupakan seni budaya yang memiliki relevansi dengan kehidupan modern, sehingga layak untuk tetap di lestarikan, khususnya oleh segmen umat Islam pandemennya.

\section{KESIMPULAN}

Seni budaya wayang merupakan karya asli masyarakat Indonesia khususnya jawa. Seni budaya wayang merupakan identitas bangsa Indonesia, wayang dalam bentuknya yang sekarang, adalah hasil karya ciptaan Walisongo yang merupakan warisan adiluhur bagi umat Islam. Wayang pernah menjadi media yang efektif untuk daerah di masa Walisongo, khususnya Sunan Kalijaga dan wayang masih relevan dengan kehidupan modern dan layak untuk tetap dilestarikan oleh umat Islam.

\section{DAFTAR PUSTAKA}

Abdurrahman, Muslim. 2003. Dakwah Kultural, Jakarta, Pustaka

Amin, Darori. 2000. Islam \& Kebudayan Jawa, Yogya, Gama Media

Amir, Hazmin. 1979. Nilai-nilai Etis Wayang, Jakarta, Pustaka Sinar Harapan

\footnotetext{
${ }^{20}$ Zarkasi Efendi, Unsur-unsur Islam dalam Pewayangan, (Solo: Yayasan Mardi Kintoko, 1996). hal. 128-129
} 
Arifin, Muhammad. 2004. Dakwah Kontemporer, Surabaya, Pustaka Agung Harapan

Aziz, Ali. 2004. Ilmu Dakwah, Jakarta, Prenada Media

Bachtiar, Wardi. 1997. Metodologi Penelitian Dakwah, Jakarta, Logos

Efendi, Zarkasi. 1996. Unsur-unsur Islam dalam Pewayangan, Solo, Yayasan Mardi Kintoho.

Martosoedono. 1995. Sejarah Wayang, Semarang, Dahara Prize.

Munir, Muhammad. 2009. Metode Dakwah, Jakarta, Prenada Media

Poejosubroto. 1978. Wayang Lambang Ajaran Islam, Jakarta, Paramita.

Purwadi. 2007. Dakwah Sunan Kalijaga, Yogya, Pustaka Pelajar.

Simuh. 1999. Sufisme Jawa, Yogyakarta, Bintang Budaya

Soetarno. 1995. Wayang Kulit Jawa, Sukoharjo, Cendrawasih.

Sulthon, M. 2003, Desain Ilmu Dakwah, Yogya, Pustaka Pelajar.

Sunarto. 1989. Wayang Kulit Purwo, Semarang, Dahara Prize.

Sutrisno. 1972. Dunia Wayang dan Sejarahnya, Surakarta, ASKI

Ya’qub, Hamzah. 1981. Publisistik Islam, Bandung, CV. Diponegoro. 